\title{
BMJ Open A randomised trial deploying a simulation to investigate the impact of hospital discharge letters on patient care in general practice
}

\author{
Moyez Jiwa, ${ }^{1}$ Xingqiong Meng, ${ }^{2}$ Carolyn O'Shea, ${ }^{3}$ Parker Magin, ${ }^{4}$ Ann Dadich, ${ }^{5}$ \\ Vinita Pillai ${ }^{1}$
}

To cite: Jiwa M, Meng $X$, O'Shea C, et al. A randomised trial deploying a simulation to investigate the impact of hospital discharge letters on patient care in general practice. BMJ Open 2014;4:e005475.

doi:10.1136/bmjopen-2014005475

- Prepublication history and additional material is available. To view please visit the journal (http://dx.doi.org/ 10.1136/bmjopen-2014005475).

Received 15 April 2014 Revised 27 May 2014 Accepted 18 June 2014

CrossMark

For numbered affiliations see end of article.

Correspondence to Professor Moyez Jiwa; M.Jiwa@curtin.edu.au

\section{ABSTRACT}

Objective: To determine how the timing and length of hospital discharge letters impact on the number of ongoing patient problems identified by general practitioners (GPs).

Trial design: GPs were randomised into four groups. Each viewed a video monologue of an actor-patient as he might present to his GP following a hospital admission with 10 problems. GPs were provided with a medical record as well as a long or short discharge letter, which was available when the video was viewed or 1 week later. GPs indicated if they would prescribe, refer or order tests for the patient's problems.

Methods: Setting Primary care. Participants Practising Australian GPs. Intervention A short or long hospital discharge letter enumerating patient problems. Outcome measure Number of ongoing patient problems out of 10 identified for management by the GPs. Randomisation 1:1 randomisation. Blinding (masking) Single-blind.

Results: Numbers randomised 59 GPs. Recruitment GPs were recruited from a network of 102 GPs across Australia. Numbers analysed 59 GPs. Outcome GPs who received the long letter immediately were more satisfied with this information $(p<0.001)$. Those who received the letter immediately identified significantly more health problems $(p=0.001)$. GPs who received a short, delayed discharge letter were less satisfied than those who received a longer delayed letter $(p=0.03)$; however, both groups who received the delayed letter identified a similar number of health problems. GPs who were older, who practised in an inner regional area or who offered more patient sessions per week identified fewer health problems ( $\mathrm{p}$ values $<0.01$, $<0.05$ and $<0.05$, respectively). Harms Nil.

Conclusions: Receiving information during patient consultation, as well as GP characteristics, influences the number of patient problems addressed.

Trial registration number: ACTRN12614000403639.

\section{INTRODUCTION}

In 2011-2012, there were approximately 9.3 million discharges after admission to
Strengths and limitations of this study

- General practitioners (GPs) who receive delayed discharge letters are less likely to address patient problems following discharge from hospital.

- GPs who received a short discharge letter were less satisfied than those who received a longer letter; however, both groups addressed a similar number of health problems.

- A key strength of this study is the presentation of the same information to all GPs, regardless of the group to which they were randomly assigned

- Limitations of this study include: (1) GPs had no opportunity to interact with the actor-patient-as such, they had no opportunity to negotiate the health problems that required immediate attention with the patient and (2) they may have addressed some comorbidities during subsequent consultations.

Australian hospitals. ${ }^{1}$ The average length of stay was 5.8 days and people aged 65 years and older accounted for $48 \%$ of patient days. Australia spends more than $\$ 33$ billion annually on public hospitals, about $70 \%$ of which is on inpatient services. Given the rise of some chronic diseases ${ }^{2}$ and Australia's ageing population, ${ }^{3}$ the cost of inpatient care is expected to rise.

During an admission, a patient may develop complications or a hospital-acquired infection. ${ }^{4}$ Regular treatments or doses may be altered, or there may be adverse drug reactions or other complications. Comorbidities may also be identified and specialist follow-up care may be scheduled.

Once discharged, patients are often advised to consult their general practitioner (GP) for the management of any new or ongoing problems. ${ }^{6}$ An Australian study found that $25 \%$ visited their GP within 4 days of hospital discharge and $50 \%$ within 12 days. ${ }^{7}$ Patients may present to their GP 
requiring further medication; investigations for new or ongoing health problems; referrals to other specialists; referrals for tests or treatments or sick-leave certification. Furthermore, they or their family members may require clarification on the diagnosis, treatment, prognosis or follow-up plan. Given the varied roles assumed by the GP, primary care helps to support patients and facilitate their return to the community. 8

To inform the care needed postdischarge, GPs rely on advice from hospital clinicians who treated the patient. However, GPs are generally dissatisfied with the details provided, even when the information is supplemented by patient consultation. This can have serious implications for the patient, including the administration of incorrect medication or doses, and/or rehospitalisation, among other adverse events. ${ }^{10-12}$

Despite the reported associations between hospital discharge letters and patient health, to the best of the authors' knowledge, no research has examined whether the length and the timing of receipt of a hospital discharge letter influences GP management. There are many possible consequences associated with inadequate information transfer, including disruption to (if not loss of) continuity of care, dissatisfaction, iatrogenesis and adverse events. ${ }^{13}$ This empirical, standardised patient study addresses this evidence gap with reference to the number of ongoing patient problems that would be identified by GPs.

\section{METHODS}

Following approval from the Curtin Human Research Ethics Committee (No: RD-11-13), 102 GPs practising in six Australian states and territories were invited to participate in this simulation study, from June 2012 to September 2013, via three channels. These included: (1) Divisions of General Practice, which (at the time of the study) were geographically defined professional bodies that supported members and promoted primary care; (2) the authors' university departments, which had previously conducted research involving GPs and (3) the authors' personal networks of GPs. The Divisions, the university departments and the authors invited GPs to participate in this study via email and personal contact. Following informed consent, GPs were provided with information via email regarding study participation. They were remunerated with $\$ A 25$ for their contribution.

GPs were randomly assigned to one of four groups, A-D, by the study coordinator using a computergenerated numbering system. All GPs started the study by viewing a $5 \mathrm{~min}$ video-recording of a monologue by an actor-patient as he might present to a GP after leaving the hospital (see online supplementary appendix 1 video file). This was viewed online at the GPs' own location. The actor described his ideas, concerns and expectations about his current health (see table 1). The issues described were drawn from the cases of several anonymous patients who were under the recent care of a general surgeon $(\mathrm{RH})$. The video was supplemented with case notes of medical, family and drug history, which were provided to all GPs at the time the video was viewed. To optimise face validity, the monologue and case notes were reviewed by researcher-clinicians, including a surgeon ( $\mathrm{RH})$, two GPs (MJ and $\mathrm{CO}$ ) and a pharmacist (AR).

GPs assigned to groups A $(n=11)$ and C $(n=16)$ received a discharge letter at the time the video was viewed, while those assigned to groups $B(n=18)$ and $D$ $(\mathrm{n}=14)$ received this letter 1 week later (see table 2$)$. Furthermore, groups A and B received a short letter of 450 words (see online supplementary appendix 2), while groups $\mathrm{C}$ and $\mathrm{D}$ received a longer letter of 911 words (see online supplementary appendix 3). After the video, all GPs completed a survey comprised of closed and open-ended items, representing phase I of the study (see online supplementary file). Survey data revealed the health problems identified by the GPs; their proposed action(s) - notably, prescription, referral or test; their views on the health of the actor-patient; and appropriate care. Groups B and D were invited to complete the survey for a second time, 1 week later, after receiving the discharge letter-this represents phase II of the study.

The aforementioned researchers identified 10 health problems that a GP might address after viewing the video, the previous case notes and the discharge letter. These were classified according to urgency, ranging from urgent (I) to not urgent (IV).

Given the influence of documented patient information on clinical judgement, ${ }^{14}$ groups $\mathrm{A}$ and $\mathrm{C}$ were anticipated to identify twice as many health problems, relative to groups B and D. For this reason, a sample of 20 GPs per group was deemed sufficient in this exploratory study to estimate the effect size of an immediate discharge letter, within $95 \%$ CIs ranging from $0 \%$ to $34 \% .^{15}$

Fisher's exact test was used to determine group differences in: (1) the number of health problems identified after the video and (2) GP ratings of timeliness, information content and the utility of the short and long referral letters. Linear regression was used to determine group differences in the average number of health problems identified by the GPs. The full regression model included: the four GP groups, age, sex, country of graduation, years after graduation, years of GP experience, status as established GP or GP registrar (trainee), fellowship status with the Royal Australian College of General Practitioners (FRACGP), the remoteness of their primary practice, the number of GPs at their primary practice, and status as a principal within their primary practice. Binary logistic regression models were used to determine: (1) the probability that the health problems would be identified and (2) the influence of letter-length and demographic information. In addition to the aforementioned variables, a full binary logistic regression model included the health problems. 


\section{Table 1 Participants $(n=59)$}

\begin{tabular}{|c|c|c|c|}
\hline & \multicolumn{2}{|c|}{ Sample } & \multirow{2}{*}{$\begin{array}{l}\text { National population* } \\
\text { Mean }\end{array}$} \\
\hline & Mean & SD & \\
\hline \multicolumn{4}{|l|}{ GP demographics } \\
\hline Age (years) & 44 & 11.1 & 50.5 \\
\hline Years after graduation & 20 & 11.2 & \\
\hline Years of GP experience & 15 & 11.4 & \\
\hline GP sessions/week & 7 & 2.9 & \\
\hline \multirow[t]{2}{*}{ Number of GPs in the clinic } & 8 & 4.2 & \\
\hline & $\mathbf{N}$ & Per cent & Per cent \\
\hline Male & 31 & 52.5 & 60.9 \\
\hline Graduated in Australia & 41 & 69.5 & 65.9 \\
\hline Registrars & 11 & 18.6 & 3.8 \\
\hline FRACGP & 37 & 62.7 & 56.8 \\
\hline Principals & 13 & 22 & \\
\hline \multicolumn{4}{|l|}{ Primary practice demographics } \\
\hline Accredited & 59 & 100.0 & 88.6 \\
\hline \multicolumn{4}{|l|}{ Location } \\
\hline ACT & 1 & 1.7 & 1.5 \\
\hline NSW & 7 & 11.9 & 33.1 \\
\hline QLD & 5 & 8.5 & 19.5 \\
\hline SA & 5 & 8.5 & 8.4 \\
\hline TAS & 0 & 0.0 & 2.6 \\
\hline VIC & 14 & 23.7 & 25.1 \\
\hline WA & 27 & 45.8 & 9.1 \\
\hline \multicolumn{4}{|l|}{ Remoteness } \\
\hline Major city & 42 & 71.2 & 71.1 \\
\hline Inner regional & 9 & 15.2 & 18.9 \\
\hline Outer regional & 4 & 6.8 & 8.1 \\
\hline Remote & 4 & 6.8 & 0.9 \\
\hline \multicolumn{4}{|l|}{ Patient consultations } \\
\hline \multicolumn{4}{|l|}{ Patient consultation $\mathrm{h} /$ week } \\
\hline$<11$ & 7 & 11.9 & 1.2 \\
\hline $11-20$ & 11 & 18.6 & 12.2 \\
\hline $21-40$ & 30 & 50.9 & 53.0 \\
\hline $41-60$ & 10 & 16.9 & 32.1 \\
\hline$>60$ & 1 & 1.7 & 1.4 \\
\hline \multicolumn{4}{|l|}{ Non-English consultations } \\
\hline No & 47 & 79.7 & \\
\hline$<25 \%$ & 11 & 18.6 & 21.7 \\
\hline$>50 \%$ & 1 & 1.7 & 2.8 \\
\hline
\end{tabular}

Regression models were constructed using both backward elimination and forward selection. Variables with a $p$ value of less than 0.05 were retained in the final model and reported, with the exception of the variable of the intervention group, which remained in the model regardless of the significance level. Stata V.12.1 (StataCorp LP, College Station, Texas, USA) was used to perform the analyses. Multivariate regression models were adjusted for the lack of independence between individual GPs by estimating the clustered SEs to account for intragroup correlation (vce option in Stata).

\section{RESULTS}

Fifty-nine GPs were recruited (response rate 57.8\%; see online supplementary appendix 4 consort diagram).
Approximately half were male $(52.5 \%)$ and the average age was 44 years (see table 1). Six states and territories were represented, with the highest proportions of GPs practising in Western Australia (45.8\%) and Victoria $(23.7 \%)$. National GP data suggest that the participants were younger with a greater proportion of registrars and of clinicians who worked shorter hours.

\section{Health problems identified}

After viewing the video, GPs in all four groups identified relatively few of the 10 health problems (median 2; IQR $0-4$; see table 2). Those who received the discharge letter at the time of viewing the video (groups $\mathrm{A}$ and $\mathrm{C}$ ) considered this to be timely (see table 3) and identified significantly more health problems. They were more 
Table 2 Health problems identified immediately after video $(n=59)$

\begin{tabular}{|c|c|c|c|c|c|c|c|c|c|}
\hline \multirow[b]{3}{*}{ Health issue } & \multicolumn{8}{|c|}{ Health problems identified } & \multirow[b]{3}{*}{ p Value* } \\
\hline & \multicolumn{2}{|c|}{ Group A } & \multicolumn{2}{|c|}{ Group B } & \multicolumn{2}{|c|}{ Group C } & \multicolumn{2}{|c|}{ Group D } & \\
\hline & $\mathbf{N}$ & Per cent & $\mathbf{N}$ & Per cent & $\mathbf{N}$ & Per cent & $\mathbf{N}$ & Per cent & \\
\hline 1. Hypertension & 2 & 18.2 & 0 & 0.0 & 1 & 6.3 & 0 & 0.0 & 0.11 \\
\hline 2. Diabetes & 2 & 18.2 & 5 & 27.8 & 1 & 6.3 & 1 & 7.1 & 0.31 \\
\hline 3. Glaucoma & 1 & 9.1 & 2 & 11.1 & 0 & 0.0 & 0 & 0.0 & 0.41 \\
\hline 4. Asthma & 2 & 18.2 & 4 & 22.2 & 8 & 50.0 & 2 & 14.3 & 0.14 \\
\hline 5. Thyroid nodule & 9 & 81.8 & 2 & 11.1 & 16 & 100.0 & 0 & 0.0 & $<0.001$ \\
\hline 6. Anticoagulation & 4 & 36.4 & 6 & 33.3 & 3 & 18.8 & 3 & 21.4 & 0.69 \\
\hline 7. Social support & 3 & 27.3 & 5 & 27.8 & 5 & 31.3 & 1 & 7.1 & 0.40 \\
\hline 8. Pulmonary embolism & 2 & 18.2 & 2 & 11.1 & 1 & 6.3 & 0 & 0.0 & 0.46 \\
\hline 9. Colorectal cancer & 4 & 36.4 & 3 & 16.7 & 9 & 56.3 & 0 & 0.0 & 0.002 \\
\hline 10. Anxiety & 6 & 54.6 & 9 & 50.0 & 13 & 81.2 & 2 & 14.3 & 0.003 \\
\hline \multicolumn{10}{|c|}{ Number of identified problems } \\
\hline Mean \pm SD & \multirow{2}{*}{\multicolumn{2}{|c|}{$\begin{array}{l}3.2 \pm 2.2 \\
0 \text { (ref. group) }\end{array}$}} & \multicolumn{2}{|c|}{$2.1 \pm 2.5$} & \multicolumn{2}{|c|}{$3.6 \pm 1.5$} & \multicolumn{2}{|c|}{$0.6 \pm 1.5$} & \\
\hline $\begin{array}{l}\text { Coefficient† } \\
95 \% \mathrm{Cl}+\end{array}$ & & & \multicolumn{2}{|c|}{$\begin{array}{l}-1.07 \\
(-2.29 \text { to } 0.45)\end{array}$} & \multicolumn{2}{|c|}{0.38} & \multicolumn{2}{|c|}{$\begin{array}{l}-2.54 \\
(-4.14 \text { to } 0.94)\end{array}$} & 0.001 \\
\hline
\end{tabular}

* $p$ Values derived from Fisher's exact test.

†Results are derived from a linear regression and overall $p$ value is derived from the Wald test.

inclined to focus on the thyroid nodule, patient understanding of colorectal cancer and patient anxiety. GPs who received a short letter 1 week later (group B) were more likely to address hypertension than those who received the long letter 1 week later (group D; see table 4).

\section{Factors that influenced the identified health problems}

The linear regression models indicate that GPs who received the long discharge letter, 1 week after the video (group D), identified significantly fewer health problems, relative to those who viewed a discharge letter immediately after the video (groups A and C; see table 5). However, there were no differences in the number of health problems identified between those who received the immediate letter (groups $\mathrm{A}$ and $\mathrm{C}$ ) and those who received the short discharge letter, 1 week after the video (group B). GPs who were older, who practised in an inner regional area or who offered more patient sessions per week identified fewer health problems. Conversely, GPs who had practised as a GP for a longer period, who practised in an outer regional area or who practised for $21 \mathrm{~h}$ or more per week identified more health problems. The linear regression models demonstrate that the GPs who received the long discharge letter, 1 week after the video (group D), identified significantly fewer health problems than those who received the long letter immediately after the video (group C); however, there were no significant correlations with demographic factors.

The binary logistic regression models indicate that, compared to hypertension, all GPs were more likely to identify other health problems, except the pulmonary embolism and glaucoma. GPs who received the long letter 1 week after the video (group D) were less likely to identify the health problems. The binary logistic regression models also demonstrate that GPs who received the delayed discharge letter (groups B and D) were more likely to identify the thyroid nodule, anticoagulation and colorectal cancer, relative to hypertension.

\section{DISCUSSION}

GPs who received the hospital discharge letter at the time of patient consultation, rather than 1 week later, addressed more of the patient's problems. When the doctors viewed the video, the groups that had already received the discharge letter-regardless of whether it was short or long (groups A and C)-considered the letter to be timely. Furthermore, GPs who received these timely letters identified more health problems, relative to their counterparts who received the delayed letters. Therefore, the hospital discharge letter has a demonstrated impact on the number of problems actioned by GPs during an initial patient consultation, postdischarge. A significant and unexpected finding in this study was that older GPs and those who worked longer hours and/or in outer regional areas addressed fewer problems than others. This may reflect the experience of more established practitioners or practitioners in more rural areas who might expect that patients such as the one depicted in the video are likely to return to them many times in subsequent weeks and months. Therefore, it may have been deemed reasonable to address fewer problems on an initial visit and tackle some of the other issues later. We also noted that GPs who worked a greater number of sessions addressed fewer problems than those who claimed to work longer hours. One might reasonably expect the two categories to be correlated; however, as participants were not 
Table 3 GP views on discharge letter $(n=59)$

\begin{tabular}{|c|c|c|c|c|c|c|c|c|c|}
\hline & \multicolumn{2}{|c|}{ Group A } & \multicolumn{2}{|c|}{ Group B } & \multicolumn{2}{|c|}{ Group C } & \multicolumn{2}{|c|}{ Group D } & \multirow[b]{2}{*}{ p Value* } \\
\hline & $\mathbf{N}$ & Per cent & $\mathbf{N}$ & Per cent & $\mathbf{N}$ & Per cent & $\mathbf{N}$ & Per cent & \\
\hline \multicolumn{10}{|c|}{ Immediate discharge letter } \\
\hline \multicolumn{10}{|c|}{ Timely } \\
\hline Yes & 11 & 100.0 & 1 & 5.6 & 16 & 100.0 & 0 & 0.0 & $<0.001$ \\
\hline No & 0 & 0.0 & 17 & 94.4 & 0 & 0.0 & 13 & 92.9 & \\
\hline Unsure & 0 & 0.0 & 0 & 0.0 & 0 & 0.0 & 1 & 7.14 & \\
\hline \multicolumn{10}{|l|}{ Satisfaction } \\
\hline Very satisfied & 0 & 0.0 & & & 8 & 50.0 & & & $<0.001$ \\
\hline Satisfied & 4 & 36.4 & & & 6 & 37.5 & & & \\
\hline Neutral & 0 & 0.0 & & & 2 & 12.5 & & & \\
\hline Dissatisfied & 7 & 63.6 & & & 0 & 0.0 & & & \\
\hline \multicolumn{10}{|l|}{ Would prescribe } \\
\hline Yes & 3 & 27.3 & 3 & 16.7 & 4 & 25.0 & 1 & 7.1 & 0.51 \\
\hline No & 4 & 36.4 & 11 & 61.1 & 5 & 31.2 & 8 & 57.1 & \\
\hline Unsure & 4 & 36.4 & 4 & 22.2 & 7 & 43.8 & 5 & 35.7 & \\
\hline \multicolumn{10}{|c|}{ Would request investigation } \\
\hline Yes & 8 & 72.7 & 10 & 55.6 & 16 & 100.0 & 3 & 21.4 & $<0.001$ \\
\hline No & 2 & 18.2 & 3 & 16.7 & 0 & 0.0 & 8 & 57.1 & \\
\hline Unsure & 1 & 9.1 & 5 & 27.8 & 0 & 0.0 & 3 & 21.4 & \\
\hline \multicolumn{10}{|c|}{ Would make a referral } \\
\hline Yes & 4 & 36.4 & 2 & 11.1 & 5 & 31.2 & 1 & 7.1 & 0.38 \\
\hline No & 5 & 45.4 & 10 & 55.6 & 9 & 56.3 & 10 & 71.4 & \\
\hline Unsure & 2 & 18.2 & 6 & 33.3 & 2 & 12.5 & 3 & 21.4 & \\
\hline \multicolumn{10}{|c|}{ Would schedule another appointment } \\
\hline Yes & 1 & 9.1 & 9 & 50.0 & 5 & 31.2 & 9 & 64.3 & 0.03 \\
\hline No & 10 & 90.9 & 9 & 50.0 & 11 & 68.8 & 5 & 35.7 & \\
\hline \multicolumn{10}{|c|}{ Delayed discharge letter } \\
\hline Satisfaction & & & 0 & 0.0 & & & 4 & 28.6 & 0.03 \\
\hline Very satisfied & & & 7 & 38.9 & & & 8 & 57.1 & \\
\hline Satisfied & & & 2 & 11.1 & & & 0 & 0.0 & \\
\hline Neutral & & & 6 & 33.3 & & & 1 & 7.1 & \\
\hline Dissatisfied & & & 3 & 16.7 & & & 1 & 7.1 & \\
\hline \multicolumn{10}{|c|}{ Very dissatisfied } \\
\hline \multicolumn{10}{|l|}{ Would prescribe } \\
\hline Yes & & & 9 & 50.0 & & & 7 & 50.0 & 0.06 \\
\hline No & & & 6 & 33.3 & & & 1 & 7.1 & \\
\hline Unsure & & & 0 & 0.0 & & & 4 & 28.6 & \\
\hline No response & & & 3 & 16.7 & & & 2 & 14.3 & \\
\hline \multicolumn{10}{|c|}{ Would request investigation } \\
\hline Yes & & & 15 & 83.3 & & & 11 & 78.6 & 0.54 \\
\hline No response & & & 3 & 16.7 & & & 3 & 21.4 & \\
\hline \multicolumn{10}{|c|}{ Would make a referral } \\
\hline Yes & & & 6 & 33.3 & & & 3 & 21.4 & 0.22 \\
\hline No & & & 4 & 22.2 & & & 8 & 57.1 & \\
\hline Unsure & & & 5 & 27.8 & & & 1 & 7.1 & \\
\hline No response & & & 3 & 16.7 & & & 2 & 14.3 & \\
\hline \multicolumn{10}{|c|}{ Would schedule another appointment } \\
\hline Yes & & & 2 & 11.1 & & & 2 & 14.3 & 0.60 \\
\hline No & & & 16 & 88.9 & & & 12 & 85.7 & \\
\hline
\end{tabular}

${ }^{*} p$ Values are derived from Fisher's exact test.

guided by a definition of a 'session', it is possible that the question of 'how many sessions' was not consistently answered by the participants.

Groups A and C were much less likely to schedule another patient appointment. Furthermore, at this first point in the study, those who received the long letter during patient consultation (group C) identified more health problems, relative to those who received the short letter at this time (group A); however, the difference was not significant. This finding suggests that the longer letter may be superior. This was confirmed by the greater satisfaction of group C compared to group A. Even 
Table 4 Health problems identified on receipt of delayed discharge letter $(n=32)$

\begin{tabular}{|c|c|c|c|c|c|}
\hline \multirow[b]{3}{*}{ Health issue } & \multicolumn{4}{|c|}{ Health problems identified } & \multirow[b]{3}{*}{ p Value* } \\
\hline & \multicolumn{2}{|c|}{ Group B } & \multicolumn{2}{|c|}{ Group D } & \\
\hline & $\mathbf{N}$ & Per cent & $\mathbf{N}$ & Per cent & \\
\hline 1. Hypertension & 6 & 33.3 & 0 & 0.0 & 0.02 \\
\hline 2. Diabetes & 4 & 22.2 & 5 & 35.7 & 0.45 \\
\hline 3. Glaucoma & 3 & 16.7 & 0 & 0.0 & 0.24 \\
\hline 4. Asthma & 4 & 22.2 & 4 & 28.6 & 0.70 \\
\hline 5. Thyroid nodule & 17 & 94.4 & 10 & 71.4 & 0.14 \\
\hline 6. Anticoagulation & 11 & 61.1 & 7 & 50.0 & 0.72 \\
\hline 7. Social support & 4 & 22.2 & 2 & 14.3 & 0.67 \\
\hline 8. Pulmonary embolism & 4 & 22.2 & 0 & 0.0 & 0.11 \\
\hline 9. Colorectal cancer & 12 & 66.7 & 8 & 57.1 & 0.72 \\
\hline 10. Anxiety & 8 & 44.4 & 2 & 14.3 & 0.12 \\
\hline \multicolumn{6}{|l|}{ Number of identified problems } \\
\hline Mean $\pm S D$ & \multicolumn{2}{|c|}{$4.1 \pm 2.1$} & \multicolumn{2}{|c|}{$2.7 \pm 1.7$} & \\
\hline Coefficient $(95 \% \mathrm{Cl}), \mathrm{p}$ value† & \multicolumn{2}{|c|}{0.00 (ref. group) } & \multicolumn{2}{|c|}{$-1.34(-2.75$ to 0.06$), 0.06$} & \\
\hline
\end{tabular}

before groups $\mathrm{B}$ and $\mathrm{D}$ received the letter 1 week later, there was a difference in the number of problems they addressed after viewing the video. The performance of group $\mathrm{D}$, which received the long letter, was inferior to that of group $\mathrm{B}$, which received the short letter. In fact, group D performed worse than all other groups. However, after groups $\mathrm{B}$ and $\mathrm{D}$ received the short and long letter, respectively, their ability to address the patient's health problems did not differ significantly. This finding suggests that the short letter may be adequate to redress the balance; however, group $\mathrm{D}$ was relatively more satisfied with their letter. Therefore, although a short, delayed letter may aid the identification of health problems, it is unlikely to be well received by GPs, relative to a long letter.

Patients like the one depicted in the video-vignette are likely to experience comorbidities. ${ }^{16}$ The GPs who participated in this study indicated a preference for the long discharge letter, suggesting that they were more satisfied with its content. However, even when presented with these letters during patient consultation, they only addressed relatively few comorbidities. The group that received the long letter at the time of consultation addressed a mean of less than 4 of the 10 health problems that the patient was deemed to have. This unexpected finding may be attributed to the format of the letter or the GP's intention to address less urgent problems (perceived or otherwise) at a later date. This unexpected finding reveals opportunities for future research to determine the influence of letter layout and other factors on the GP's ability to identify and prioritise comorbidities at the time of patient discharge from hospital.

The style of the letter may impact on perceived priorities. For instance, oncologists who tested different formats concluded that a standardised discharge letter should be informed by GP preference-however, the study did not examine the relationship between the letter format and the number of problems that were perceived as a priority by the doctor who subsequently consulted the patient. ${ }^{17}$ In the study presented in this article, GPs were significantly more likely to investigate the patient's thyroid nodule, relative to other health problems. At one level, this was unexpected as it might be argued that the thyroid nodule represents a less immediate issue than patient independence following major surgery. However, it is possible that the thyroid nodule signalled a malignancy to the participating GPs, particularly because it was identified specifically for action in the hospital discharge letter. It may be that some of the other more immediate and practical matters might be prioritised in a bona fide patient. Also, patients like the one depicted are likely to consult their GP frequently over the course of a year. Research shows that $9.5 \%$ of general practice consultations address three problems and $3.3 \%$ address four problems ${ }^{18}$; these findings might denote the upper limit of problems that can be reasonably addressed during a general practice consultation. It is therefore probable that the GPs would have addressed the comorbidities in due course. Many GPs did not address the comorbidities-they may not have considered these as priorities, particularly because the patient had been in the recent care of hospital clinicians. Furthermore, the actor-patient may not have drawn enough attention to the problems. This follows evidence that clinician decisions are shaped by the concerns conveyed by patients. ${ }^{19}$ As such, although the discharge letters influenced GP decisions, they represent only one source of information that doctors are known to consider. $^{20-22}$ Patient ideas, concerns and expectations conveyed (explicitly or implicitly) may also lead or mislead clinicians. It may be valuable in a future study to explore the cognitive reasoning for the prioritisation of issues addressed by different GPs. 
Table 5 Regression models

\begin{tabular}{|c|c|c|c|c|c|c|c|c|c|}
\hline \multirow[b]{3}{*}{ Variables } & \multicolumn{4}{|c|}{ Linear regression models (number of health problems identified) } & \multirow[b]{3}{*}{ Variables } & \multicolumn{4}{|c|}{$\begin{array}{l}\text { Binary logistic regression models (likelihood that the health } \\
\text { problems would be identified) }\end{array}$} \\
\hline & \multicolumn{2}{|c|}{ Model 1: phase I } & \multicolumn{2}{|c|}{ Model 2: phase II } & & \multicolumn{2}{|c|}{ Model 3: phase I } & \multicolumn{2}{|c|}{ Model 4: phase II } \\
\hline & Coefficient & $(95 \% \mathrm{Cl})$ & Coefficient & $(95 \% \mathrm{Cl})$ & & $\overline{\text { OR }}$ & $(95 \% \mathrm{Cl})$ & $\overline{\text { OR }}$ & $(95 \% \mathrm{Cl})$ \\
\hline Group & & & & & Health problems & & & & \\
\hline A & 0.00 (ref) & - & & & Hypertension & 1.00 (ref) & - & 1.00 (ref) & - \\
\hline B & -0.52 & $(-1.84$ to 0.79$)$ & 0.00 (ref) & - & Diabetes & 3.62 & $(1.10 \text { to } 11.95)^{*}$ & 1.72 & (0.53 to 5.63$)$ \\
\hline C & 0.92 & $(-0.28$ to 2.12$)$ & & & Glaucoma & 1.00 & $(0.17$ to 5.82$)$ & 0.44 & (0.13 to 1.47$)$ \\
\hline$D$ & -2.25 & $(-3.64 \text { to }-0.87)^{\star \star}$ & -1.34 & $(-2.69 \text { to } 0.00)^{*}$ & Asthma & 8.18 & $(2.14 \text { to } 31.37)^{\star \star}$ & 1.46 & (0.4 to 5.33$)$ \\
\hline Age & -0.15 & $(-0.25 \text { to }-0.05)^{\star \star}$ & - & - & Thyroid nodule & 21.75 & $(6.73 \text { to } 70.24)^{\star \star \star}$ & 26.01 & $(8.07 \text { to } 83.88)^{\star \star \star}$ \\
\hline Years of GP experience & 0.15 & $(0.06 \text { to } 0.24)^{\star \star \star}$ & - & - & Anti-coagulation & 8.18 & $(2.18 \text { to } 30.74)^{\star \star}$ & 5.91 & $(2.19 \text { to } 15.93)^{\star \star \star}$ \\
\hline Remoteness & & & & & Social support & 6.67 & $(2.22 \text { to } 20.05)^{\star \star *}$ & 1.00 & (0.27 to 3.75$)$ \\
\hline Major city & 0.00 (ref) & - & & & Pulmonary embolism & 1.77 & $(0.36$ to 8.81$)$ & 0.61 & (0.19 to 2.02$)$ \\
\hline Inner regional & -1.35 & $(-2.41$ to -0.29$)$ * & & & Colorectal cancer & 8.18 & $(2.13 \text { to } 31.47)^{\star \star}$ & 7.74 & $(2.68 \text { to } 22.4)^{\star * *}$ \\
\hline Outer regional & 2.68 & $(0.60 \text { to } 4.76)^{*}$ & & & Anxiety & 28.01 & $(8.62 \text { to } 91.00)^{\star \star \star}$ & 2.01 & (0.77 to 5.22$)$ \\
\hline Remote & 0.88 & $(-1.03$ to 2.78$)$ & & & Group & & & & \\
\hline Patient sessions per week & -0.36 & $(-0.58 \text { to }-0.13)^{\star *}$ & - & & $A$ & 1.00 (ref) & & & \\
\hline Patient consultation $\mathrm{h} /$ week & & & & & B & 0.70 & (0.24 to 2.08$)$ & 1.00 (ref) & \\
\hline$<11$ & 0.00 (ref) & - & & & C & 1.58 & (0.69 to 3.66$)$ & & \\
\hline $11-20$ & 1.35 & $(-0.17$ to 2.87$)$ & & & $\mathrm{D}$ & 0.14 & $(0.03 \text { to } 0.67)^{\star}$ & 0.44 & $(0.2 \text { to } 0.99)^{*}$ \\
\hline $21-40$ & 2.30 & $(0.75 \text { to } 3.84)^{\star *}$ & & & $\begin{array}{l}\text { Patient sessions } \\
\text { per week }\end{array}$ & 0.79 & $(0.63 \text { to } 0.99)^{*}$ & - & - \\
\hline \multirow[t]{5}{*}{$\geq 41$} & 4.29 & $(2.18 \text { to } 6.41)^{\star * *}$ & & & $\begin{array}{l}\text { Patient consultation } \\
\mathrm{h} / \text { week }\end{array}$ & & & & \\
\hline & & & & & $<11$ & 1.00 (ref) & & & \\
\hline & & & & & $11-20$ & 1.97 & (0.49 to 7.82$)$ & & \\
\hline & & & & & $21-40$ & 5.63 & (0.92 to 34.55$)$ & & \\
\hline & & & & & $\geq 41$ & 14.61 & $(1.68 \text { to } 127.3)^{\star}$ & & \\
\hline
\end{tabular}


A key strength of this study is the presentation of the same information to all GPs, regardless of the group to which they were randomly assigned. This includes the video-recording and the supplementary case notes. This design provides comparative value across the four groups and thus increases the veracity of the findings. Despite this strength, three limitations warrant consideration. First, the GPs were presented with a standardised case with no opportunity to interact with the actorpatient. As such, they had no opportunity to negotiate the health problems that required immediate attention. Second, the case was very complex with a plethora of comorbidities and competing priorities. Thus, the GPs may have addressed some comorbidities during subsequent consultations. They were also being asked to make decisions on the complex case of an individual, albeit an actor, whom they had not seen earlier, even though they had access to his medical records. In practice, many such patients may be receiving more continuity of care than is suggested by this scenario. Finally, fewer GPs were recruited than originally hoped for and we also noted that the participating GPs were not representative of all Australian GPs. Although this may have influenced the views expressed, the study did accommodate varying GP characteristics in the regression analysis.

\section{CONCLUSIONS}

This study suggests that a delayed discharge letter is associated with several implications. In addition to increasing the burden on GPs, it engenders a need for a subsequent GP appointment; it limits GP capacity to respond to patient concerns and queries, at least on one occasion; it may result in a re-referral to the specialist; and it increases GP dissatisfaction with the care provided to the patient by the hospital. It is important that hospital discharge letters convey information concisely and clearly; yet it is equally important for patients to direct clinician attention to the most important problems. How a patient presents to a GP during a consultation may determine the number and type of problems addressed on any occasion. Data from this standardised patient study suggest that hospital discharge letters are important for follow-up care; however, the length of the letter is not a reliable proxy for their perceived helpfulness in aftercare. This study suggests that the care of patients with complex problems following hospital discharge may require more than one GP visit. Furthermore, this care may be influenced by how the patient presents, as much as their records, or what was communicated about their progress in a hospital discharge letter. In this study, the demographic characteristics impacted on the outcomes of the study in ways that could not be explained within the scope of the study.

\footnotetext{
Author affiliations

${ }^{1}$ Department of Medical Education, Curtin University, Perth, Western Australia, Australia

${ }^{2}$ Faculty of Health Science, School of Public Health, Curtin University, Perth, Western Australia, Australia
}

${ }^{3}$ Curtin Health Innovation Research Institute, Curtin University, Perth, Western Australia, Australia

${ }^{4}$ Discipline of General Practice, University of Newcastle, Newcastle, New South Wales, Australia

${ }^{5}$ School of Business, University of Western Sydney, Parramatta, New South Wales, Australia

Contributors MJ, PM and CO oversaw the design of the study. MJ and VP oversaw the collection of data. MJ and VP implemented the study. XM analysed the data. All authors interpreted the data, prepared the report and approved the final version.

Funding Curtin University Primary Health Care Research and Information Service grant No. 001.

Competing interests None.

Ethics approval Curtin Human Research Ethics Committee.

Provenance and peer review Not commissioned; externally peer reviewed.

Data sharing statement Extra data can be accessed via the Dryad data repository at http://datadryad.org/ with the doi:10.5061/dryad.bs200.

Open Access This is an Open Access article distributed in accordance with the Creative Commons Attribution Non Commercial (CC BY-NC 4.0) license, which permits others to distribute, remix, adapt, build upon this work noncommercially, and license their derivative works on different terms, provided the original work is properly cited and the use is non-commercial. See: http:// creativecommons.org/licenses/by-nc/4.0/

\section{REFERENCES}

1. AlHW (Australian Institute of Health and Welfare). Australian hospital statistics 2011-2012. Health services series. Canberra: AlHW (Australian Institute of Health and Welfare), 2011.

2. ABS (Australian Bureau of Statistics). Australian health survey: First results, 2011-2012. Secondary Australian health survey: first results, 2011-2012 [Website] 7 June 2013. http://www.abs.gov.au/ausstats/ abs@.nsf/Lookup/4364.0.55.001main+features12011-12

3. DCITA (Department of Communications ITatA. Australia's demographic challenges. Canberra: Australian Government, 2004.

4. Richards MJ, Russo PL. Surveillance of hospital-acquired infections in Australia-one nation, many states. J Hosp Infect 2007;65(Suppl 2):174-81

5. O'Connor MN, Gallagher P, Byrne S, et al. Adverse drug reactions in older patients during hospitalisation: are they predictable? Age Ageing 2012;41:771-6.

6. de Weerd L, Rutgers WAF, Groenier $\mathrm{KH}$, et al. Perceived wellbeing of patients one year post stroke in general practice-recommendations for quality aftercare. BMC Neurol 2011;11:1-10.

7. Roughead EE, Kalisch LM, Ramsay EN, et al. Continuity of care: when do patients visit community healthcare providers after leaving hospital? Intern Med J 2011;41:662-7.

8. Fertig AR, Corso PS, Balasubramaniam D. Benefits and costs of a free community-based primary care clinic. J Health Hum Serv Adm 2012;34:456-70.

9. Macinko J, Starfield B, Shi L. Quantifying the health benefits of primary care physician supply in the United States. Int J Health Serv 2007;37:111-26.

10. Bergkvist $A$, Midlöv $P$, Höglund $P$, et al. Improved quality in the hospital discharge summary reduces medication errors-LIMM Landskrona integrated medicines management. Eur J Clin Pharmacol 2009;65:1037-46.

11. Briggs $\mathrm{AM}$, Lee $\mathrm{N}$, Sim M, et al. Hospital discharge information after elective total hip or knee joint replacement surgery: a clinical audit of preferences among general practitioners. Australas Med J 2012;5:544-50.

12. Jiwa M, Freeman J, Tanner S. Correspondence between healthcare professionals: an evaluation of a medical student workshop on the importance of the discharge letter. Educ Primary Care 2006;17: 155-61.

13. Arora VM, Prochaska ML, Farnan JM, et al. Problems after discharge and understanding of communication with their primary care physicians among hospitalized seniors: a mixed methods study. J Hosp Med 2010;5:385-91.

14. Pothier D. Pilot study to show the loss of important data in nursing handover. Br J Nurs 2005;14:1090-93. 
15. Hertzog MA. Considerations in determining sample size for pilot studies. Res Nurs Health 2008;31:180-91.

16. Gross C, Gross Z, Guo G, et al. Multimorbidity and survival in older persons with colorectal cancer. J Am Geriatr Soc 2006;54:1898-904.

17. Braun TC, Hagen NA, Smith C, et al. Oncologists and family physicians. Using a standardized letter to improve communication. Can Fam Physician 2003;49:882-6.

18. Britt $\mathrm{H}$, Miller GC, Henderson J, et al. General practice activity in Australia 2012-13. Sydney: Sydney University Press, 2013.

19. Zimmermann C, Zimmermann L, Del Piccolo A. Cues and concerns by patients in medical consultations: a literature review. Psychol Bull 2007:133:438-63.

20. DiCenso A, Cullum N, Ciliska D. Implementing evidence-based nursing: some misconceptions. Evid Based Nurs 1998;1:38-40.
21. Rycroft-Malone J, Seers $\mathrm{K}$, Titchen A, et al. What counts as evidence in evidence-based practice? J Adv Nurs 2004; 47:81-90

22. Ferlie EB, Shortell SM. Improving the quality of health care in the United Kingdom and the United States: a framework for change. Milbank Q 2001;79:281-315.

23. AlHW (Australian Institute of Health and Welfare). Medical workforce 2010. Canberra: AlHW (Australian Institute of Health and Welfare), 2012.

24. Britt $\mathrm{H}$, Miller GC, Henderson J, et al. General practice activity in Australia 2011-12. General practice series. Sydney: University of Sydney, 2012

25. General Practice Education and Training Limited. Annual report. Canberra: General Practice Education and Training Limited, 2012. 